\title{
Use of Visual Triage in the Early Identification and Isolation of Acute Respiratory Infection Cases for the Control of Hospital Outbreak/Infection in Reference to Middle East Respiratory Syndrome- Corona Virus (MERS CoV)
}

\author{
Ibrahim Saifi Al Harbi ${ }^{1}$, Sanjay Kumar Gupta ${ }^{2, *}$
}

\begin{abstract}
Introduction: Middle East Respiratory Syndrome (MERS) is a viral respiratory disease caused by a novel coronavirus (Middle East Respiratory Syndrome Coronavirus, or MERS-CoV) that was first identified in Saudi Arabia in 2012. Since then more than 1400 cases were reported from KSA with substantial mortality of about $40 \%$. Objective: To know the role of visual triage in early identification of acute respiratory infection cases in reference to (MERS-CoV). Material and Methods: Hospital Based cross sectional study. Results: This study was carried out to find the effectiveness of visual triage in timely isolation and control of acute respiratory infection in the health care settings. During January to December 2017 total patients passes through visual triage were $1,36,516$, out of that $2240(1.64 \%)$ reported scores 4 and more. During same period $181(0.13 \%)$ of patients admitted in various wards from visual triage. Conclusion: Visual triage is very useful in timely isolation of acute respiratory infection cases and prevention of hospital outbreak due to acute respiratory infection, specially disease like MERS-CoV.

Key words: General Hospital, Visual triage use, MERS-CoV, Role, Outbreak.
\end{abstract}

\section{INTRODUCTION}

Middle East Respiratory Syndrome (MERS) is a viral respiratory disease caused by a novel coronavirus (Middle East Respiratory Syndrome Coronavirus or MERS-CoV) that was first identified in Saudi Arabia

Ibrahim Saifi Al Harbi", Sanjay Kumar Gupta ${ }^{2, *}$

'Department of IPC, IPC Director Al Rass General Hospital AI Rass, SAUDI ARABIA. ${ }^{2}$ Department of IPC, IPC Medical coordinator Ar Rass General HospitalAI Raas, SAUDI ARABIA.

\section{Correspondence}

Dr. Sanjay Kumar Gupta

Department of IPC, IPC Medical

coordinator Ar Rass General Hospital-Al

Raas, KSA.

Phone no: +966-016-0553618341

Email: Sanjaygupta2020@gmail.com

\section{History}

- Submission Date: 16-05-2018;

- Revised Date: 14-11-2018;

- Accepted Date: 06-02-2019.

DOI : 10.5530/ijmedph.2019.1.3

Article Available online

http://www.ijmedph.org/v9/i1

\section{Copyright}

(C) 2019 Phcog.Net. This is an openaccess article distributed under the terms of the Creative Commons Attribution 4.0 International license.

in 2012. Since then more than 1400 cases were reported from kingdom of Saudi Arabia KSA with substantial mortality of about $40 \%{ }^{1}$ For the prevention of cross infection and hospital outbreak suspected cases with acute respiratory infection symptoms were isolated in the point of entry so we can able to prevent cross infection among other patients and health care workers. Visual triage was played vital role in the isolation of the patient at the entry point. MERS-CoV symptoms include fever, cough and shortness of breath. Pneumonia is common, but not always present. Although some human cases of MERS-CoV have been responsible for human-to-human infections in health care settings, current scientific evidence indicates that dromedary camels are a major reservoir for MERS-CoV and an animal source of MERS-CoV infection in humans. ${ }^{2}$ Visual triage is the area with nursing station located in front of the entrance of the emergency department for assessment of the each patient according to acute respiratory form scoring.

\section{Objectives}

To know the role of visual triage use in the early identification of acute respiratory infection cases in reference to (MERS-CoV) attending in emergency department in the last one year.

\section{MATERIAL AND METHODS}

Present study was carried out in the tertiary care general hospital of Qassim provenance to know the effective use of visual triage for early identification of acute respiratory infection cases. In this regard we were made compulsory policy for each and every patients to pass through visual triage (allow to pass only those who are critically ill) area and assessed by visual triage Nurse according to respiratory triage score form. given the score and put the stamp, if score less than 4 he /she will go to Canadian triage room. If score more than or equal to 4 then patients were send to respiratory waiting area after offering hand hygiene, teaching about cough etiquette and offered surgical mask. The telephone extension line provided to visual triage counter for informing Doctors for early management of cases. If any patients was pass through without assessment from visual triage, than registration Triage nurse was filled the respiratory triage form and
Cite this article : Harbi ISA, Gupta SK. Use of Visual Triage in the Early Identification and Isolation of Acute Respiratory Infection Cases for the Control of Hospital Outbreak/Infection in Reference to Middle East Respiratory Syndrome- Corona Virus (MERS CoV). Int J Med Public Health. 2019;9(1):8-12. 
staff and doctor will not entertain this patients and send him back to visual triage area for assessment, in other words no patients would be seen or entertain by registration staff/ doctor without respiratory score form for MERS-CoV with stamp.

\section{Case definition and surveillance guidance}

\section{A. Suspected case (patients who should be tested for MERS-CoV) ${ }^{1,3}$}

a. Adults $(>14 \text { years })^{*}$

I. Acute respiratory illness with clinical and/or radiological, evidence of pulmonary parenchymal disease (pneumonia or Acute Respiratory Distress Syndrome). ${ }^{4}$

II. A hospitalized patient with healthcare associated pneumonia based on clinical and radiological evidence.

III. Upper or lower respiratory illness within 2 weeks after exposure to a confirmed or probable case of MERS-CoV infection. ${ }^{2,5}$

IV. Unexplained acute febrile $\left(\geq 38^{\circ} \mathrm{C}\right)$ illness and body aches, headache, diarrhea or nausea/vomiting, with or without respiratory symptoms and leucopenia $(\mathrm{WBC}<3.5 \times 109 / \mathrm{L})$ and thrombocytopenia (platelets $<150 \times 109 / \mathrm{L}$ ). ${ }^{6}$

V. Unexplained febrile illness with recent (14 days) exposure to camels or camel products 1 .

VI. History of contact with camels or camel products in the 14 days prior to onset of symptoms

b. Pediatrics ( $\leq 14$ years $)^{7}$

I. Meets the above case definitions and has at least one of the following:

a. History of exposure to a confirmed or suspected MERS in the 14 days prior to onset of symptoms

b. History of contact with camels or camel products in the 14 days prior to onset of symptoms

II. Unexplained severe pneumonia

* Patients with chronic kidney disease and those with heart failure could present atypically and high index of suspicion is required

B. Probable case: A probable case is a patient in category I or II above (Adults and pediatrics) with inconclusive laboratory results for MERS$\mathrm{CoV}$ and other possible pathogens who is a close contact ${ }^{5}$ of a laboratory-confirmed MERS-CoV case or who works in a hospital where MERS$\mathrm{CoV}$ cases are cared for or had recent contact with camels or camel's products.

C. Confirmed case: A confirmed case is a suspected case with laboratory confirmation of MERS-CoV infection. ${ }^{6}$

All patients attending emergency room (except those with immediately life-threatening conditions) were triaged at the entrance using predefined scoring. Identified ARI patients should be asked to perform hand hygiene and wear a surgical mask. They isolated and evaluated immediately in an area separate from other patients. We develop dedicated waiting area for the ARI patients with spatial separation of at least 1.2 meter between each ARI patient and others. Post visual alerts (in appropriate languages) at the entrance of healthcare facilities (e.g., emergency rooms). Messages in the visual alerts include the following:

1) Cover your mouth and nose with a tissue when coughing or sneezing.

2) Dispose of the tissue in the nearest waste receptacle immediately after use.

3) Perform hand hygiene (e.g., hand washing with non-antimicrobial soap and water, alcohol-based hand sanitizer, or antiseptic hand wash) after having contact with respiratory secretions and contaminated objects or materials.

4) Prevent overcrowding in clinical areas to reduce the risk of transmission between patients and to staff.
Sample of visual triage form used for assessment and scoring at visual triage station. (It represented Appendix given 1).

Nursing station nurse was asked the question to the patient according to acute respiratory checklist so if any patient having fever she will give score of 2 and he/she also having cough she again give score 2 and also having history of chronic renal failure than she will give score 1 now the total score for this patient was 5 it means he/she was needed to isolate in isolation room. For further assessment Doctor will assess all these patients in the respiratory isolation room for MERS-CoV/H1N1. If doctors feel patient is stable, he/she not required for further investigation than he will discharge the patients from ER department after treatment, if he feel patients required further managements, he will admit the patient and send to concerned department.

\section{RESULTS}

This study was carried out to find the effectiveness of visual triage in timely isolation and control of acute respiratory infection in the health care settings. Table 1 showed that during January to December 2017 total patients passes through visual triage were $1,36,516$, out of that 2240 (1.64\%) case were able to find out with scores of 4 and more. It means because of visual triage we were able to isolated acute respiratory infection suspected cases for the H1N1/MERS-CoV around 2240 cases, by that way we also able to prevent perceived outbreak in the hospital. During same period because of visual triage we were admitted 181 (0.13\%) of patients in various wards from visual triage. If we compare the patients passing through before visual triage significant number of cases we were missed for the isolation had score scores 4 and more. If we look for admission of suspected cases in various wards from visual triage also significantly increased in comparison to before visual triage scenario.

Graph 1 showed regarding cases passed through visual triage on monthly basis and Graph 2 depicted out of total cases passed monthly how many reported score 4 and more.

Graph 3 showed about admission from visual triage every month in various wards.

Graph 4 showed Total sample tested for H1N1 and MERS-CoV in whole year were 181 , out of that $24(13.25 \%)$ came positive for influenza $(\mathrm{H} 1 \mathrm{~N} 1=22$ and Influenza B=2) and no case reported positive for MERS$\mathrm{CoV}$.

\begin{tabular}{|c|c|c|c|}
\hline $\begin{array}{c}\text { Serial } \\
\text { Number }\end{array}$ & Category & Number & Percentages \\
\hline 1 & $\begin{array}{l}\text { Total number of cases passes } \\
\text { through visual triage (138298) in } \\
2017\end{array}$ & $1,36,916$ & $99 \%$ \\
\hline 2 & $\begin{array}{l}\text { Number of cases scored } 4 \text { and more } \\
\text { from visual triage out of total cases } \\
\text { passes }(\mathrm{N}=136916) \text { in } 2017\end{array}$ & 2240 & $1.64 \%$ \\
\hline 3 & $\begin{array}{l}\text { Number of cases admitted in wards } \\
\text { from visual triage out of total cases } \\
\qquad(\mathrm{N}=136916) \text { in } 2017\end{array}$ & 181 & $0.13 \%$ \\
\hline 4 & $\begin{array}{l}\text { Number of cases admitted in wards } \\
\text { from visual triage out of score } 4 \text { and } \\
\text { more }(\mathrm{N}=2240) \text { in } 2017\end{array}$ & 181 & $8 \%$ \\
\hline
\end{tabular}




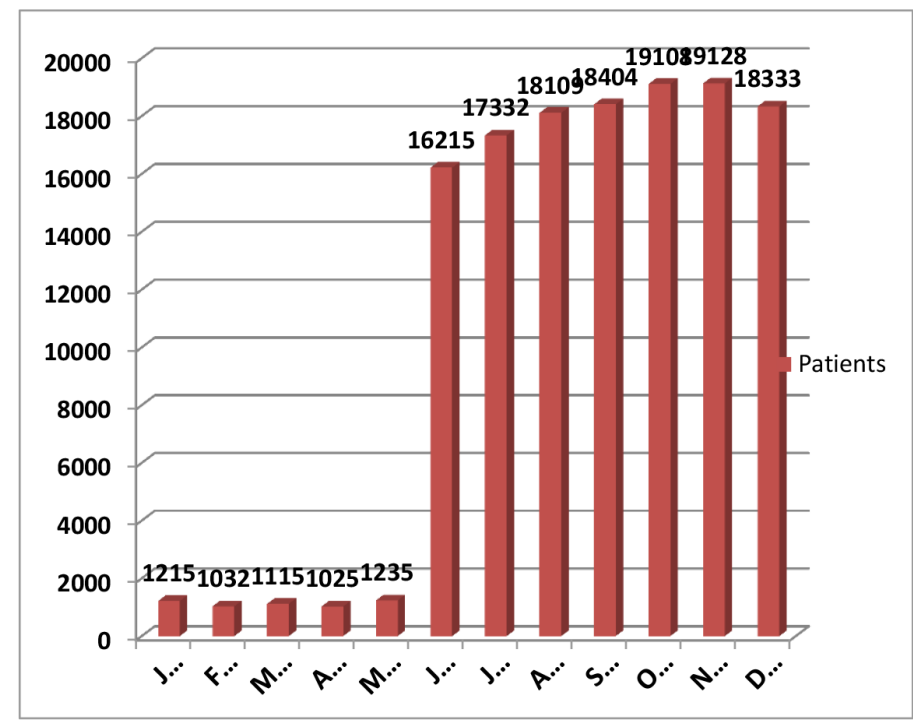

January to December -2017.

Graph 1: Number of Patients Monthly Passes through visual triage From Month of January to December -2017.

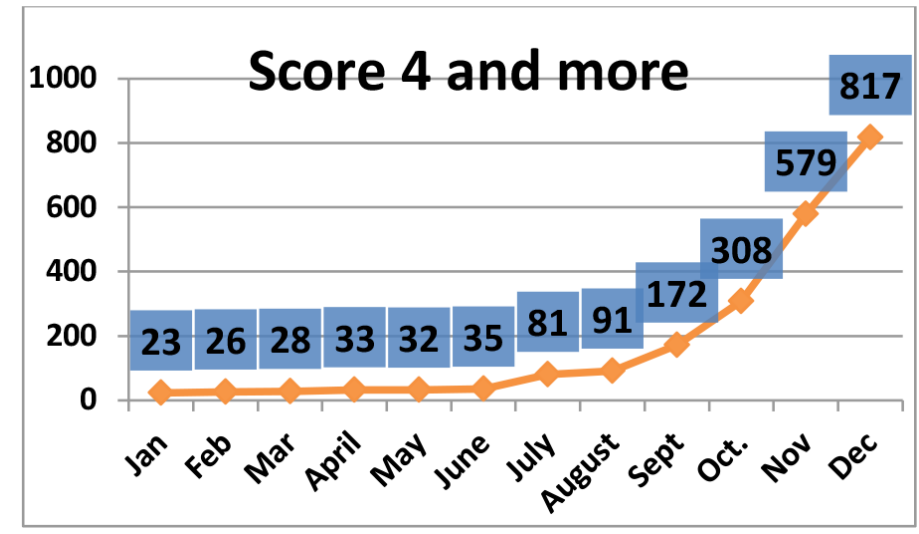

Graph 2: Number of cases score 4 or more Monthly from visual triage area and isolated (Jan-Dec) in 2017.

\section{Cases admitted}

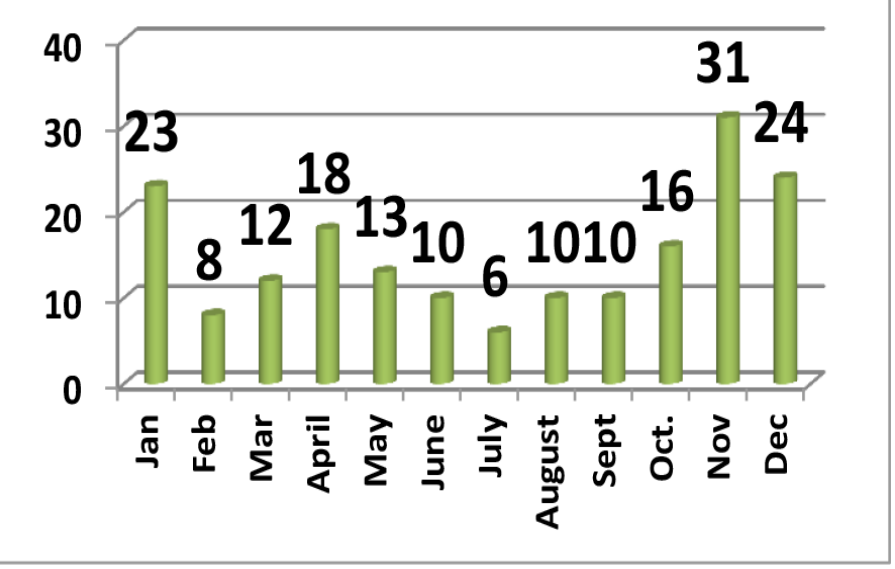

Graph 3: Number of Suspected/Probable Cases of MERS-CoV, Admitted in Pediatric, MMW, FMW, MSW and ICU from months of January to December 2017 from ER Visual Triage (Out of 4 or more Score).

\section{H1N1 Positive}

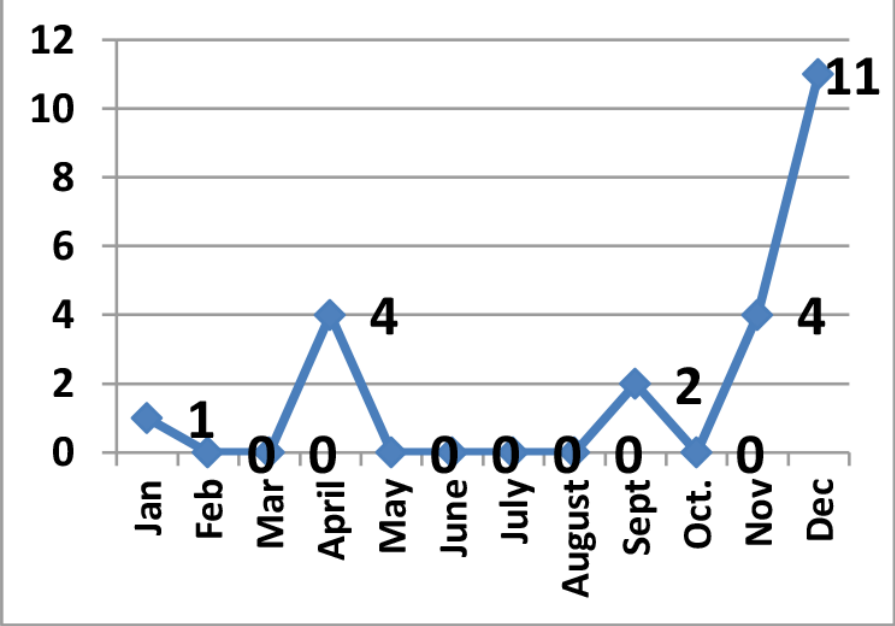

Graph 4: Monthly status of Number of H1N1 cases reported positive in 2017 (Jan-Dec).

\section{DISCUSSION}

No study we were able to find regarding usefulness of the visual triage for the early detection of the acute respiratory infection cases in reference to H1N1/MERS CoV, majority of study focused on the importance of visual triage in the hospital, site and area, role and patient flow. The Guidelines published by Traiq A Madani regarding infection prevention and control of MERS CoV infection they also mentioned the role of visual triage for early identification acute respiratory infection cases and also mentioned the importance of visual triage in the hospital outbreak control. ${ }^{7}$ Guidelines provided by WHO regarding prevention and control of coronavirus in health care settings they also mention role of visual triage in early detection of acute respiratory infection cases and control of outbreak in the hospital. ${ }^{8} \mathrm{CDC}$ also develop interim guidelines for the prevention and control of MERS CoV in the health care setting they also mentioned the importance of the visual triage in early identification of the acute respiratory infection cases and prevention of hospital outbreak, visual triage play very crucial role for prevention and control of MERS CoV/H1N1 among health care professionals. ${ }^{9}$ The article published in The Lancet about MERS CoV definition and management they also reported the role of visual triage in control of acute respiratory infection case by offering hand hygiene, cough etiquette, surgical mask and isolation of the patient according to acute respiratory checklist score, if score 4 and more isolation of the patients. ${ }^{10}$

\section{CONCLUSION}

Visual triage is very useful in timely detection, isolation of acute respiratory infection cases and prevention of cross infection and also helpful in the prevention of hospital outbreak due to acute respiratory infection, specially disease like H1N1/MERS-CoV.

\section{ACKNOWLEDGEMENT}

We are very thankful to emergency department for helping in data collection in this research. 


\section{CONFLICT OF INTEREST}

The authors declare that there is no conflict of interest.

\section{ABBREVIATIONS}

MERS CoV: Middle East Respiratory Syndrome Corona Virus; WHO : World Health Organization; CDC: Centre for Disease Control and Prevention.

\section{SUMMARY}

The visual triage was very useful for timely detection of acute respiratory infection cases and their isolation, in this way we were able to prevent hospital outbreak. Number of cases significantly were increases in winter season from the month of October to December, majority of cases admitted in medical wards from visual triage.

\section{REFERENCES}

1. Interim Guidelines for Collecting, Handling and Testing Clinical Specimens from Patients Under Investigation (PUIs) for Middle East Respiratory Syndrome
Coronavirus (MERS-CoV) - Version 2. Centers for Disease Control and prevention (CDC). 2014.

2. Biosafety in Microbiological and Biomedical Laboratories (BMBL) $5^{\text {th }}$ Edition. 2009. Centers for Disease Control and prevention (CDC).

3. Laboratory testing for novel coronavirus: Interim recommendations. World Health Organization (WHO). 2012.

4. Interim Laboratory Biosafety Guidelines for Handling and Processing Specimens Associated with Middle East Respiratory Syndrome Coronavirus (MERS-CoV). Centers for Disease Control and prevention (CDC)

5. Laboratory bio risk management for laboratories handling human specimens suspected or confirmed to contain novel coronavirus: Interim recommendations. World Health Organization (WHO). 2017;53.

6. Laboratory Biosafety Manual - $3^{\text {rd }}$ Edition. World Health Organization. 2004.

7. Tariq AM, Abdulhakeem OA, Alraddadi BM. Infection prevention and control guidelines for patients with Middle East Respiratory Syndrome Coronavirus (MERS-CoV) infection. Saudi Med J. 2014;35(8):861-64.

8. World Health Organization. Infection prevention and control during health care for probable or confirmed cases of novel coronavirus (nCoV) infection. Interim Guidance. [Updated 2013 May 6].

9. Centers for Disease Control and Prevention. Interim Infection Prevention and Control Recommendations for Hospitalized Patients with Middle East Respiratory Syndrome Coronavirus (MERS-CoV). [Updated 2014 May 14].

10. MadaniTA. New case definition and management algorithm for patients infected with MERS-Coronavirus in Saudi Arabia Lan.

Cite this article : Harbi ISA, Gupta SK. Use of Visual Triage in the Early Identification and Isolation of Acute Respiratory Infection Cases for the Control of Hospital Outbreak/Infection in Reference to Middle East Respiratory Syndrome- Corona Virus (MERS CoV). Int J Med Public Health. 2019;9(1):8-12. 
Not any case reported positive for MERS-CoV during January to Dec 2017.

Note: Two cases reported positive for influenza $B$ virus.

KINGDOM OF SAUDI ARABIA

Ministry of Health

General Direcorate Of Health Affairs

Al-qassim Province

Al-rass General Hospital

Infection Control Department

Date : Time :
المملكة العربية السعودية وزارة الصحة الصـة المديرية العامة للشؤونة الصحة الصحية بمنطقة القصامة التصام مستشفى الرس العانمة القوام قسمر مكافحة العدمى العدام

Name :

Age : Sex :

National / Residence Id :

Visual Triage : Acute Repiratory Illness Checklist For MERS-cov

ADULTS

\begin{tabular}{|c|c|c|c|}
\hline \multicolumn{2}{|r|}{ A. Clinical Symptoms / Sign } & Points & Score \\
\hline 1 & History Of Fever $\left(<38^{\circ} \mathrm{c}\right)$ حرارة & 2 & \\
\hline 2 & Cough (New Or Worsening) & 2 & \\
\hline 3 & Shortness Of Breath (New Or Worsening) & 2 & \\
\hline 4 & Nausea / Vomiting غثيان إستفراغ Diarrgea سهال! & 1 & \\
\hline 5 & ألم بالحلق . سيلان بالانف Sore Throat And / Or Runny Nose & 1 & \\
\hline 6 & Dm, Chronic Renal Failure , Cad / Heart Failure & 1 & \\
\hline \multicolumn{4}{|c|}{$\begin{array}{r}\text { B. Risk Of Exposure To MERS } \\
\end{array}$} \\
\hline 7 & Exposure To Mers In Last 2 Weeks & 3 & \\
\hline 8 & Exposure To Camel Or Products (Direct Or Indirect*) In Last 14 Days & 2 & \\
\hline 9 & Visit To Health Care Facility That Has Mers Case In Last 2 Weeks & 1 & \\
\hline & المجموع الكلي Total Score & & \\
\hline
\end{tabular}

PEDIATRICS

\begin{tabular}{|l|l|c|c|}
\hline \multicolumn{1}{|c|}{ A. Clinical Symptoms / Sign } & Points & Score \\
\hline 1 & Fever $\left(\geq 38^{\circ}\right.$ c) & 1 & \\
\hline 2 & Cough (New Or Worsening) & 1 & \\
\hline 3 & Shortness Of Breath (New Or Worsening) & 1 & \\
\hline \multicolumn{1}{|c|}{ B. Risk Of Exposure To MERS } & & \\
\hline 4 & Exposure To Confirmed MERS case in last two weeks \\
\hline 5 & $\begin{array}{l}\text { Exposure To Camel Or Products (Direct Or Indirect*) In } \\
\text { The Last Two Weeks }\end{array}$ & 3 & \\
\hline 6 & $\begin{array}{l}\text { Visit To Health Care Facility That Has Mers Case In Last } \\
\text { Two Weeks }\end{array}$ & 1 & \\
\hline \multicolumn{2}{|l|}{ Total Score } & & \\
\hline
\end{tabular}

\section{* Patient or Houshold}

a score $\geq 4$, Place patient in an isolation room and inform MD for assessment

ID Number : Stuff Nurse : 